\section{(2) OPEN ACCESS}

\title{
Severe proximal muscle weakness with normal CK as a presenting feature of ANCA-associated vasculitis
}

\author{
Sureshkumar Nagiah 이, ${ }^{1}$ Daunda Mudiyanselage Manodhi Saranapala ${ }^{2}$
}

${ }^{1}$ General Medicine, Flinders Medical Centre, Bedford Park, South Australia, Australia ${ }^{2}$ Endocrinology, Royal Adelaide Hospital, Adelaide, South Australia, Australia

Correspondence to Dr Sureshkumar Nagiah; sureshkumar.nagiah@health. sa.gov.au

Accepted 10 January 2020

\section{SUMMARY}

Antineutrophil cytoplasmic antibodies associated vasculitis (AAV) presenting with muscle weakness is rarely reported. We report a case of myeloperoxidase positive vasculitis presenting with severe proximal muscle weakness with normal creatine kinase and no positron-emission tomography uptake. There was a significant delay in the diagnosis of AAV due to atypical presentation. We propose AAV be considered in the differential diagnosis of proximal muscle weakness after excluding the common causes.

\section{BACKGROUND}

Antineutrophil cytoplasmic antibodies (ANCA)associated vasculitis (AAV) is predominantly a small vessel vasculitis. The patients usually present with non-specific symptoms such as fever, weight loss, headache, respiratory symptoms and joint pains. Muscle weakness with or without raised creatine kinase $(\mathrm{CK})$ is not commonly listed as a presenting feature of AAV in the medical literature. When a patient presents with non-specific symptoms with muscle weakness, a normal CK or normal imaging cannot rule out myositis or vasculitis. A muscle biopsy should be considered even in the presence of a normal CK or negative vasculitis screening. Also, a normal MRI or positron-emission tomography (PET) scan cannot convincingly rule out myositis or vasculitis.

\section{CASE PRESENTATION}

An 82-year-old man presented with fever and cough on a background of a 6-week history of generalised weakness and fatigue. He also described a fall with his legs giving way underneath him. He did not lose consciousness. His admission temperature was $39.1^{\circ} \mathrm{C}$. He had a cough with purulent sputum production. A chest X-ray and CT chest did not show any consolidation or inflammatory changes. However, he was started on a course of moxifloxacin for a chest infection with the resolution of his fever and was subsequently discharged home.

Three weeks later, the patient represented with another fall at home secondary to his legs giving way. He also described significant fatigue, myalgia, weakness and night sweats over the last 3 months. He was previously highly functioning and was able to garden and paint walls independently. $\mathrm{He}$ also described a $6 \mathrm{~kg}$ weight loss during this period. There was no history of headache or jaw claudication. He denied any urinary or other infective symptoms. His background history included dietcontrolled diabetes and hyperlipidaemia. He was not taking any regular medications.

On examination, the patient had profound proximal muscle weakness (Medical Research Council muscle power-grade 3) and was unable to stand up from a seated position without support. His distal lower limb muscle power was normal. His upper limbs were unaffected. The reflexes, sensory system and the rest of the neurological examination were normal.

\section{Investigations}

Biochemical parameters are shown in table $1 . \mathrm{He}$ had an elevated white cell count and neutrophils on presentation, and this has slightly improved after the course of antibiotics for a probable chest infection. C-reactive protein (CRP) remained elevated on the second presentation. Since he had progressive muscle weakness, he underwent further investigations for secondary causes for muscle weakness.

CK was within normal limits on repeated testing. Thyroid-stimulating hormone was normal. Screening for infectious illnesses including cytomegalovirus, Epstein-Barr virus and HIV was negative. Connective tissue disease screening was also undertaken. The antinuclear antibody was weakly positive. The ANCA testing showed that he had a moderately positive myeloperoxidase (MPO) antibody titre. This was originally considered as a nonsignificant result due to a low titre, and the positive result was attributed to the infective illness.

As this man had progressive and debilitating muscle weakness, further testing was undertaken. The clinicians were reluctant to consider a muscle biopsy given that he had a repeatedly normal CK. PET scan did not show any uptake in any muscle group.

A search for malignancy screening including CT scan of the abdomen, pelvis and the chest was normal, making a paraneoplastic process less likely. Finally, a muscle biopsy of the left vastus lateralis was performed, and it revealed marked fibrinoid necrosis of the medium-sized arterial walls with an intense transmural mixed inflammatory infiltrate (figure 1).

\section{TREATMENT}

The patient was commenced on high-dose prednisolone $80 \mathrm{mg}(1 \mathrm{mg} / \mathrm{kg})$, and it was tapered to $30 \mathrm{mg}$ over a period of 3 weeks. He had steroid-induced 


\begin{tabular}{|c|c|c|c|}
\hline & $\begin{array}{l}\text { First } \\
\text { presentation }\end{array}$ & $\begin{array}{l}\text { Second } \\
\text { presentation } \\
\text { ( } 3 \text { weeks after } \\
\text { first) }\end{array}$ & $\begin{array}{l}\text { Normal } \\
\text { range }\end{array}$ \\
\hline CK (U/L) & * & 211 & $0-250$ \\
\hline WCC (/L) & 11.92 & 10.91 & $4-11$ \\
\hline Platelet (/L) & 540 & 426 & $150-450$ \\
\hline CRP (mg/L) & 182.2 & 176.9 & $0-8$ \\
\hline Sodium (mmol/L) & 134 & 135 & $135-145$ \\
\hline Creatinine (umol/L) & 82 & 66 & $60-110$ \\
\hline Albumin (g/L) & 22 & 18 & $34-48$ \\
\hline Aspartate transaminase (U/L) & 32 & 55 & $0-45$ \\
\hline Alanine transaminase (U/L) & 24 & 36 & $0-55$ \\
\hline Gamma-glutamyl transferase(U/L) & 55 & 163 & $0-60$ \\
\hline Alkaline phosphatase (U/L) & 77 & 181 & $30-110$ \\
\hline Bilirubin (umol/L) & 4 & 6 & $2-24$ \\
\hline TSH (mIU/L) & 1.10 & * & $0.5-4.5$ \\
\hline Free T4 (pmol/L) & * & * & $10-25$ \\
\hline ANA & $1: 80$ (speckled) & * & \\
\hline Myeloperoxidase (IU/mL) & 33 & * & $\leq 5$ \\
\hline Proteinase three antibody (IU/mL) & 0 & * & $\leq 5$ \\
\hline Urine albumin/creatinine ratio & 0.9 & * & $0-2.5$ \\
\hline
\end{tabular}

*Not performed.

ANA, antinuclear antibody; CK, creatine kinase; CRP, C-reactive protein; TSH, Thyroidstimulating hormone; WCC, white cell count.

hyperglycaemia during this period which was managed with protaphane insulin.

\section{OUTCOME AND FOLLOW-UP}

The patient responded rapidly with fever subsiding within days after starting the high-dose steroids. The muscle weakness improved gradually, and he was subsequently discharged home without needing any rehabilitation. He was treated with long term prednisolone and rituximab infusions to maintain remission. The patient was independent in all activities of daily living

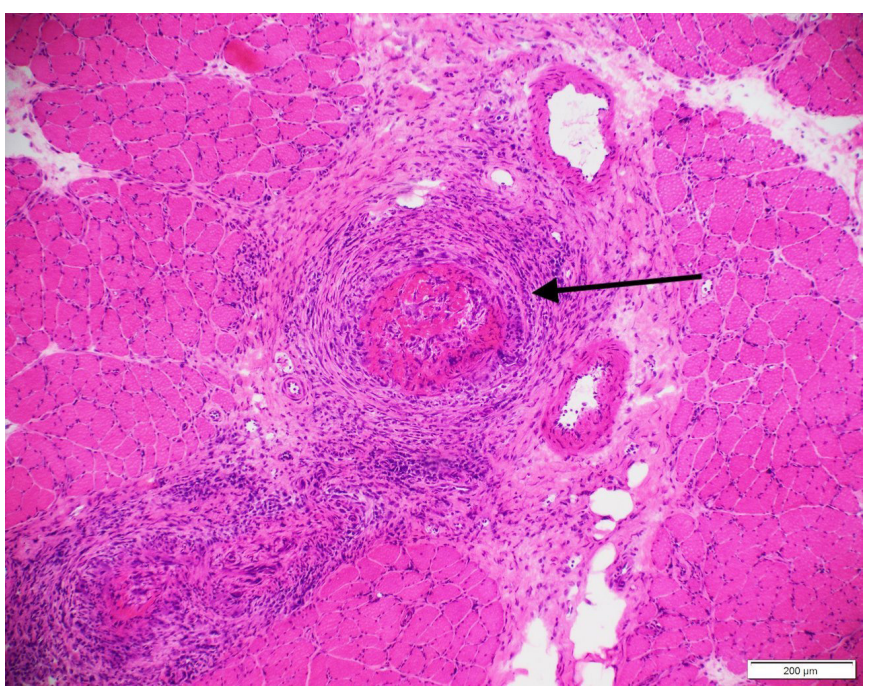

Figure 1 Histopathologic features of left vastus lateralis muscle showing marked fibrinoid necrosis of the medium-sized arterial walls with an intense transmural mixed inflammatory infiltrate (arrow). There is no extension of inflammatory cells into intact fibres. after a couple of months into his treatment. He did not develop any renal or pulmonary complications 1 year into his treatment.

\section{DISCUSSION}

AAV is predominantly a small vessel necrotising vasculitis. They typically do not have deposition of immune complexes, and hence they are also called pauci-immune vasculitis. ${ }^{1}$ The three predominant forms of AAV are granulomatosis with polyangiitis (GPA), microscopic polyangiitis (MPA) and eosinophilic granulomatosis with polyangiitis. ${ }^{2}$ There is also a renal limited version which in clinical practice closely resembles a renal limited version of GPA or MPA. ${ }^{2}$ AAV could have the presence of circulating ANCA directed at either myeloperoxidase (MPO-ANCA) or proteinase 3 (PR3-ANCA). ${ }^{34}$

Patients with GPA and MPA are commonly described in the older adult group with a slightly higher incidence in males. There is also a higher prevalence among Caucasian and Hispanic populations. ${ }^{5}$ AAV usually present with non-specific symptoms such as fever, fatigue, weight loss, headache, respiratory symptoms and joint pains. ${ }^{6}$ There could also be skin, renal and neurological manifestations to a variable extent. The patients could present acutely within a few days or progress over many months, like in the case reported above.

Muscle weakness with or without raised CK is not commonly listed as a presenting feature of AAV in the medical literature. A vast majority of cases of vasculitis involving the skeletal muscle group that have been reported are in patients with polyarteritis nodosa or leukocytoclastic vasculitis. ${ }^{8-10}$ Almost all these patients had severe calf muscle pain, and $50 \%$ of them also had fever on presentation. ${ }^{11-21}$ The calf was the predominantly affected site in most previously reported lower limb vasculitis. ${ }^{9}$ All these patients had a significant inflammatory response. ${ }^{9}$

There are only very few cases of AAV presenting with muscle weakness (table 2).

Our patient presented with unexplained and profound proximal muscle weakness with normal CK. There have been four other previously reported cases of AAV presenting with significant muscle weakness with normal CK. Three of the cases had pulmonary fibrosis and the presence of rheumatoid factor as an association. The case described by Kim et al also had focal necrotising glomerulonephritis as an additional feature. In our case, severe muscle weakness seems to be the only feature.

One could argue that this patient had polyarteritis nodosa rather than AAV due to a predominantly medium vessel vasculitis with marked fibrinoid necrosis of the arterial walls with an intense transmural mixed inflammatory infiltrate. However, the presence of MPO-ANCA in moderate titre (33 IU/mL (reference $\leq 5)$ ) argues against PAN. Although AAV typically involves small vessels, they could also affect medium-sized arteries. ${ }^{22}$ Given the above this patient most likely had AAV rather than PAN.

Four other reported cases had variable CK rise. Interestingly two of these cases were ANCA negative, and the other two cases had PR3-ANCA positive rather than MPO-ANCA, which was seen in all other positive cases. ${ }^{8} 23$ The reason for the negative ANCA may be due to the lack of measurable ANCA in the circulation. $^{2425}$

The MRI scans of the muscles showed oedema or abnormal fat infiltration in all the previously reported cases. Our patient did not have an MRI but had a PET scan which showed no uptake in any of the muscle groups. As shown above, all of these patients had confirmed vasculitis on muscle biopsy.

We propose a muscle biopsy should be considered in any patient with unexplained muscle pain or proximal myopathy even if the 
Table 2 Characteristics of previously reported cases of AAV with muscle weakness

\begin{tabular}{|c|c|c|c|c|c|c|c|c|}
\hline & Age/ sex & Muscle involvement & CK (U/L) & MRI/PET scan & Histology & $\begin{array}{l}\text { Other organ } \\
\text { involvement }\end{array}$ & ANCA & $\begin{array}{l}\text { CRP } \\
(\mathrm{mg} / \mathrm{L})\end{array}$ \\
\hline Our patient & $82 / \mathrm{M}$ & $\begin{array}{l}\text { Severe proximal } \\
\text { weakness/myalgia }\end{array}$ & 211 & No MRI done, but PET normal & $\begin{array}{l}\text { Fibrinoid necrosis of } \\
\text { medium vessels }\end{array}$ & None & MPO & 182.2 \\
\hline Oiwa et $a l^{45}$ & $76 / F$ & Weakness/myalgia & 25 & MRI showed muscle oedema & Small vessel vasculitis & Pulmonary fibrosis & MPO & 84.52 \\
\hline Birnbaum et $a l^{46}$ & $77 / F$ & $\begin{array}{l}\text { Proximal weakness/ } \\
\text { myalgia }\end{array}$ & Normal & MRI showed muscle oedema & Perimysial vasculitis & Pulmonary fibrosis & MPO & NA \\
\hline Kim et $a l^{47}$ & $71 / \mathrm{M}$ & Calf pain & Normal & $\begin{array}{l}\text { MRI showed abnormal fat } \\
\text { infiltration }\end{array}$ & $\begin{array}{l}\text { Necrotising } \\
\text { granulomatous } \\
\text { vasculitis }\end{array}$ & $\begin{array}{l}\text { Pulmonary fibrosis } \\
\text { and Kidney (FNG) }\end{array}$ & MPO & 95.7 \\
\hline $\begin{array}{l}\text { Benz et al } \\
\text { Case } 3^{8}\end{array}$ & $64 / \mathrm{M}$ & $\begin{array}{l}\text { Myalgia/proximal } \\
\text { weakness }\end{array}$ & Normal & $\begin{array}{l}\text { MRI showed diffuse } \\
\text { inflammation }\end{array}$ & Necrotising vasculitis & None & Negative & 330 \\
\hline $\begin{array}{l}\text { Benz et al } \\
\text { Case } 1^{8}\end{array}$ & $80 / F$ & $\begin{array}{l}\text { Myalgia/proximal } \\
\text { weakness }\end{array}$ & $\begin{array}{l}\text { Eight times } \\
\text { the limit }\end{array}$ & MRI showed muscle oedema & Small vessel vasculitis. & None & Negative & 289 \\
\hline $\begin{array}{l}\text { Benz et al } \\
\text { Case } 2^{8}\end{array}$ & $79 / F$ & $\begin{array}{l}\text { Myalgia/proximal } \\
\text { weakness }\end{array}$ & $4000 \mathrm{U} / \mathrm{L}$ & $\begin{array}{l}\text { MRI showed lipomatous } \\
\text { atrophy/involution }\end{array}$ & Small vessel vasculitis & None & Negative & 380 \\
\hline Ojima et $a l^{23}$ & $58 / \mathrm{M}$ & $\begin{array}{l}\text { Myalgia/Muscle } \\
\text { weakness }\end{array}$ & $29998 U / L$ & MRI showed muscle oedema & $\begin{array}{l}\text { Fibrinoid necrosis of } \\
\text { arterioles }\end{array}$ & None & PR3 & 305 \\
\hline Akagi et al ${ }^{48}$ & $59 / \mathrm{M}$ & Calf pain & $237 \mathrm{U} / \mathrm{L}$ & MRI showed muscle oedema & $\begin{array}{l}\text { Fibrinoid necrosis of } \\
\text { arterioles }\end{array}$ & Kidney involvement & PR3 & 155 \\
\hline
\end{tabular}

AAV, ANCA-associated vasculitis ; ANCA, antineutrophil cytoplasmic antibodies; CK, creatinine kinase; F, female; FNG, focal necrotising glomerulonephritis; M, male; MPO, myeloperoxidase; NA, not available; PET, positron-emission tomography; PR3, proteinase 3.

CK levels are normal. In a study by Vital et al combined nerve and muscle biopsy of 212 patients with suspected vasculitic neuropathy, the muscle biopsy increased the yield of diagnosis of vasculitis by $27 \%$, re-iterating the usefulness of the muscle biopsy. ${ }^{26}$ In a retrospective review by Hervier et al about the use of muscle biopsy for the diagnosis of systemic vasculitis, 22 of the 33 patients who had a muscle biopsy had evidence of systemic vasculitis. ${ }^{27}$ In this cohort, the positive muscle biopsies showed either a necrotising or non-necrotising vasculitis. This series had a sensitivity of $66.7 \%$ and a specificity of over $99 \%$ for the diagnosis of systemic vasculitis. In the same series, neither muscle pain nor high CK levels correlated with a positive muscle biopsy suggestive of systemic vasculitis. ${ }^{27}$ This discrepancy in clinical and laboratory features with a positive muscle biopsy suggest that a muscle biopsy should be considered to rule out vasculitis if a patient presents with unexplained muscle weakness irrespective of CK levels.

The reason for the above clinicopathological discrepancy in muscle biopsy is unclear. Some suggest that muscle ischaemia is not seen in systemic vasculitis, possibly due to vascular compensation as opposed to patients with inflammatory myositis where there is complement-mediated lysis of endomysial capillaries, causing muscle necrosis. ${ }^{27} 28$

Once the muscle weakness from systemic vasculitis is suspected, appropriate testing should be considered. Raised inflammatory markers is a universal feature. ${ }^{9}$ If the diagnosis is unclear after the initial work-up including a connective tissue screening, further testing including targeted MRI and muscle biopsies should be considered. An MRI scan earlier in the course of the disease is very useful for diagnosis, as well for targeting muscle biopsy when required. The T1-weighted sequence with gadolinium will show enhancement. ${ }^{9}$ T2-weighted hyperintensities will usually indicate increased muscle fluid content implying muscle oedema. ${ }^{29}$ However, these changes in MRI are non-specific as they can also be seen in myopathies from trauma, metabolic and degenerative diseases. ${ }^{29}$ Muscle pain and stiffness had been the predominant clinical feature in the PAN case series. In the reported PAN cases, CK levels are often normal or only slightly increased. MRI scans had a very high sensitivity in detecting muscle involvement in most of these cases. ${ }^{29}$ MRI scans can also be used for targeting muscle biopsy to an affected area of the muscle and also possibly to monitor disease activity. ${ }^{29} 30$ In patients with dermatomyositis and polymyositis, MRI scans have been shown to be a useful tool to assess the disease activity, guide muscle biopsy as well as to, follow-up patients with serial imaging to assess response to treatment. ${ }^{31} 32$ However, this needs further confirmation, especially in patients with ANCA vasculitis.

The use of PET-CT scans to assess disease activity is used widely in large vessel vasculitis. ${ }^{24}{ }^{33-36}$ Several large studies have shown sensitivity and specificity up to $90 \%$ in patients with large-vessel vasculitis. ${ }^{33}$ The use of PET in small to medium vessel vasculitis (AAV) is controversial. ${ }^{24} 3738$ Most of the available literature is focused on patients with GPA, where suggestive PET findings help make a diagnosis, but their use in other AAV is unknown. ${ }^{37}$ In a few studies, PET-CT was highly sensitive in detecting the active focus of inflammation even in patients without CRP rise or detectable ANCA levels. ${ }^{39} 40$

\section{Learning points}

Antineutrophil cytoplasmic antibody (ANCA)-associated vasculitis (AAV) could present with isolated muscle weakness, and therefore after excluding common causes of muscle weakness, further testing should be done to rule out AAV.

- Patients with AAV could have extensive vasculitis within the muscle groups despite having a normal creatine kinase (CK) or negative ANCA. This discrepancy in laboratory features with a positive muscle biopsy suggests that a muscle biopsy should be considered to rule out vasculitis if a patient presents with unexplained muscle weakness irrespective of CK levels or ANCA titre.

- MRI has a very high sensitivity as a diagnostic test in myositis/vasculitis even in patients with normal CK. MRI can also be used to target muscle biopsy and possibly follow-up patients with myositis/vasculitis. The use of positron-emission tomography scans in AAV still needs further evaluation. 
Although PET-CT scans are used in the diagnosis of inflammatory myositis, their use has not been studied in skeletal muscle vasculitis associated with AAV, possibly because muscle involvement from AAV is not widely recognised. ${ }^{41-44}$ In our patient PET uptake was not seen despite having florid vasculitis in the muscle biopsy.

In conclusion, AAV causing muscle weakness is not commonly recognised. The patients with AAV could have extensive vasculitis within the muscle groups despite having a normal CK. Most of the reported cases had MPO-ANCA positive. MRI scans have shown to be very useful for detecting muscle oedema and for targeting muscle biopsy even in patients with normal CK. The use of PET-scans in AAV still needs further evaluation.

Contributors SN wrote most of the case presentation, discussion and drafted the tables for the manuscript. SN also consented the patient for publication. DMMS wrote some parts of the discussion and edited the manuscript several times.

Funding The authors have not declared a specific grant for this research from any funding agency in the public, commercial or not-for-profit sectors.

Competing interests None declared.

Patient consent for publication Obtained.

Provenance and peer review Not commissioned; externally peer reviewed.

Open access This is an open access article distributed in accordance with the Creative Commons Attribution Non Commercial (CC BY-NC 4.0) license, which permits others to distribute, remix, adapt, build upon this work non-commercially, and license their derivative works on different terms, provided the original work is properly cited and the use is non-commercial. See: http://creativecommons.org/ licenses/by-nc/4.0/.

\section{ORCID iD}

Sureshkumar Nagiah http://orcid.org/0000-0003-0075-5799

\section{REFERENCES}

1 Jennette JC, Nachman PH. Anca glomerulonephritis and vasculitis. Clin J Am SoC Nephrol 2017;12:1680-91.

2 Pagnoux C. Updates in ANCA-associated vasculitis. Eur J Rheumatol 2016;3:122-33.

3 Houben E, Bax WA, van Dam B, et al. Diagnosing ANCA-associated vasculitis in ANCA positive patients: a retrospective analysis on the role of clinical symptoms and the ANCA titre. Medicine 2016;95:e5096.

4 Hilhorst M, van Paassen P, Tervaert JWC, et al. Proteinase 3-ANCA vasculitis versus Myeloperoxidase-ANCA vasculitis. J Am Soc Nephrol 2015;26:2314-27.

5 Watts RA, Mahr A, Mohammad AJ, et al. Classification, epidemiology and clinical subgrouping of antineutrophil cytoplasmic antibody (ANCA)-associated vasculitis. Nephrol Dial Transplant 2015;30:114-22.

6 Berden A, Goceroglu A, Jayne D, et al. Diagnosis and management of ANCA associated vasculitis. BMJ 2012;344:e26.

7 Granulomatosis with polyangiitis and microscopic polyangiitis: Clinical manifestations and diagnosis [Internet]. UpToDate Waltham, MA: UpToDate Inc, 2019. Available: https://www.uptodate.com/contents/granulomatosis-with-polyangiitis-andmicroscopic-polyangiitis-clinical-manifestations-and-diagnosis\#H331193026 [cited 19 Sep 2019].

8 Benz N, Daikeler T, Frank S, et al. Three cases of primary small vessel vasculitis of the skeletal muscle-an own entity. BMJ Case Rep 2011;2011:bcr0820114631.

9 Khellaf M, Hamidou M, Pagnoux C, et al. Vasculitis restricted to the lower limbs: a clinical and histopathological study. Ann Rheum Dis 2007;66:554-6.

10 Carron Pet al. Case number 34: relapse of polyarteritis nodosa presenting as isolated and localised lower limb periostitis. Ann Rheum Dis 2005;64:1118-9.

11 Ferreiro JE, Saldana MJ, Azevedo SJ. Polyarteritis manifesting as calf myositis and fever. Am J Med 1986:80:312-5.

12 García F, Pedrol E, Casademont J, et al. Polyarteritis nodosa confined to calf muscles. J Rheumatol 1992;19:303-5.

13 Garcia-Porrua C, Mate A, Duran-Mariño JL. Localized vasculitis in the calf mimicking deep venous thrombosis. Rheumatology 2002;41:944-5.

14 Gardner GC, Lawrence MK. Polyarteritis nodosa confined to calf muscles. J Rheumatol 1993;20:908-9.

15 Golding DN. Polyarteritis presenting with leg pains. BMJ 1970;1:277-8.

16 Hall C, Mongey AB. Unusual presentation of polyarteritis nodosa. J Rheumatol 2001;28:871-3
17 Kamimura T, Hatakeyama M, Torigoe K, et al. Muscular polyarteritis nodosa as a cause of fever of undetermined origin: a case report and review of the literature. Rheumatol Int 2005;25:394-7

18 Laitinen 0, Haltia M, Lähdevirta J. Polyarthritis confined to lower extremities. Scand J Rheumatol 1982;11:71-4.

19 Nakamura T, Tomoda K, Yamamura Y, et al. Polyarteritis nodosa limited to calf muscles: a case report and review of the literature. Clin Rheumatol 2003;22:149-53.

20 Nash P, Fryer J, Webb J. Vasculitis presenting as chronic unilateral painful leg swelling. J Rheumatol 1988;15:1022-5.

21 Soubrier M, Bangil M, Franc $\mathrm{S}$, et al. Vasculitis confined to the calves. Revue Du Rhumatisme English Edition Joint Bone Spine Diseases 1997;64:414-6.

22 Jennette JC, Falk RJ, Bacon PA, et al. 2012 revised international chapel Hill consensus conference Nomenclature of vasculitides. Arthritis Rheum 2013:65:1-11.

23 Ojima Y, Sawada K, Fujii H, et al. Anti-Neutrophil cytoplasmic antibody-associated vasculitis (AAV) restricted to the limbs. Internal Medicine 2018:57:1301-8.

24 Farrah TE, Basu N, Dweck M, et al. Advances in therapies and imaging for systemic vasculitis. Arterioscler Thromb Vasc Biol 2019:39:1520-41.

25 Chen M, Yu F, Wang S-X, et al. Antineutrophil cytoplasmic autoantibody-negative Pauci-immune crescentic glomerulonephritis. J Am Soc Nephrol 2007;18:599-605.

26 Vital C, Vital A, Canron M-H, et al. Combined nerve and muscle biopsy in the diagnosis of vasculitic neuropathy. A 16-year retrospective study of 202 cases. J Peripher Nerv Syst 2006:11:20-9.

27 Hervier B, Durant C, Masseau A, et al. Use of muscle biopsies for diagnosis of systemic vasculitides. J Rheumato/ 2011:38:470-4.

28 Dalakas MC, Hohlfeld R. Polymyositis and dermatomyositis. Lancet 2003;362:971-82

29 Gallien Set al. Magnetic resonance imaging of skeletal muscle involvement in limb restricted vasculitis. Ann Rheum Dis 2002;61:1107-9.

30 Hofman DM, Lems WF, Witkamp TD, et al. Demonstration of calf abnormalities by magnetic resonance imaging in polyarteritis nodosa. Clin Rheumatol 1992;11:402-4.

31 Tomasová Studýnková J, Charvát F, Jarošová K, et al. The role of MRI in the assessment of polymyositis and dermatomyositis. Rheumatology 2007;46:1174-9.

32 Lassche $\mathrm{S}$, Janssen BH, IJzermans T, et al. MRI-guided biopsy as a tool for diagnosis and research of muscle disorders. J Neuromuscul Dis 2018:5:315-9.

33 Zerizer I, Tan K, Khan S, et al. Role of FDG-PET and PET/CT in the diagnosis and management of vasculitis. Eur J Radiol 2010;73:504-9.

34 Bleeker-Rovers CP, Bredie SJH, van der Meer JWM, et al. F-18-fluorodeoxyglucose positron emission tomography in diagnosis and follow-up of patients with different types of vasculitis. Neth J Med 2003;61:323-9.

35 Brodmann M, Lipp RW, Passath A. The role of 2-18F-fluoro-2-deoxy-D-glucose positron emission tomography in the diagnosis of giant cell arteritis of the temporal arteries. Rheumatology 2004;43:241-2.

36 Blockmans D, Ceuninck Lde, Vanderschueren S, et al. Repetitive18Ffluorodeoxyglucose positron emission tomography in giant cell arteritis: a prospective study of 35 patients. Arthritis Rheum 2006:55:131-7.

37 Soussan M, Abisror N, Abad S, et al. FDG-PET/CT in patients with ANCA-associated vasculitis: case-series and literature review. Autoimmun Rev 2014;13:125-31.

38 Slart RHJA, Writing group, Reviewer group, et al. FDG-PET/CT(A) imaging in large vessel vasculitis and polymyalgia rheumatica: joint procedural recommendation of the EANM, SNMMI, and the PET Interest Group (PIG), and endorsed by the ASNC. Eur J Nucl Med Mol Imaging 2018;45:1250-69.

39 Vöö S. Clinical value of 18F-fluorodeoxyglucose PET-CT in patients with small- and medium-size vessel vasculitis, such as Wegener's granulomatosis. J Nucl Med 2012:53.

40 Kemna MJ, Vandergheynst F, Vöö S, et al. Positron emission tomography scanning in anti-neutrophil cytoplasmic antibodies-associated vasculitis. Medicine 2015;94:e747-e.

41 Sun L, Dong Y, Zhang N, et al. [18F]Fluorodeoxyglucose positron emission tomography/computed tomography for diagnosing polymyositis/dermatomyositis. Exp Ther Med 2018.

42 Al-Nahhas A, Jawad ASM. Pet/Ct imaging in inflammatory myopathies. Ann N Y Acad Sci 2011:1228:39-45

43 YLaQ W. Idiopathic inflammatory myositis. J Nucl Med 2017;58.

44 Tanaka S, Ikeda K, Uchiyama K, et al. [18F]FDG uptake in proximal muscles assessed by PET/CT reflects both global and local muscular inflammation and provides useful information in the management of patients with polymyositis/dermatomyositis. Rheumatology 2013;52:1271-8.

45 Oiwa H, Kurashige T. Muscle weakness as a presenting symptom in ANCA-associated vasculitis. Eur J Rheumatol 2018:5:139-41.

46 Birnbaum J, Danoff S, Askin FB, et al. Microscopic polyangiitis presenting as a "pulmonary-muscle" syndrome: Is subclinical alveolar hemorrhage the mechanism of pulmonary fibrosis? Arthritis Rheum 2007;56:2065-71.

47 Kim MY, Bae SY, Lee M, et al. A case of ANCA-associated vasculitis presenting with calf claudication. Rheumatol Int 2012:32:2909-12.

48 Akagi T, Nishimura H, Mukai T, et al. Necrosis of the gastrocnemius muscle in microscopic polyangiitis. BMJ Case Rep 2018;33:bcr-2017-223585. 
Copyright 2020 BMJ Publishing Group. All rights reserved. For permission to reuse any of this content visit https://www.bmj.com/company/products-services/rights-and-licensing/permissions/

BMJ Case Report Fellows may re-use this article for personal use and teaching without any further permission.

Become a Fellow of BMJ Case Reports today and you can:

- Submit as many cases as you like

- Enjoy fast sympathetic peer review and rapid publication of accepted articles

- Access all the published articles

Re-use any of the published material for personal use and teaching without further permission

Customer Service

If you have any further queries about your subscription, please contact our customer services team on +44 (0) 2071111105 or via email at support@bmj.com.

Visit casereports.bmj.com for more articles like this and to become a Fellow 